\title{
The Relation of Insect Defoliation to Mortality in Connecticut Forests
}

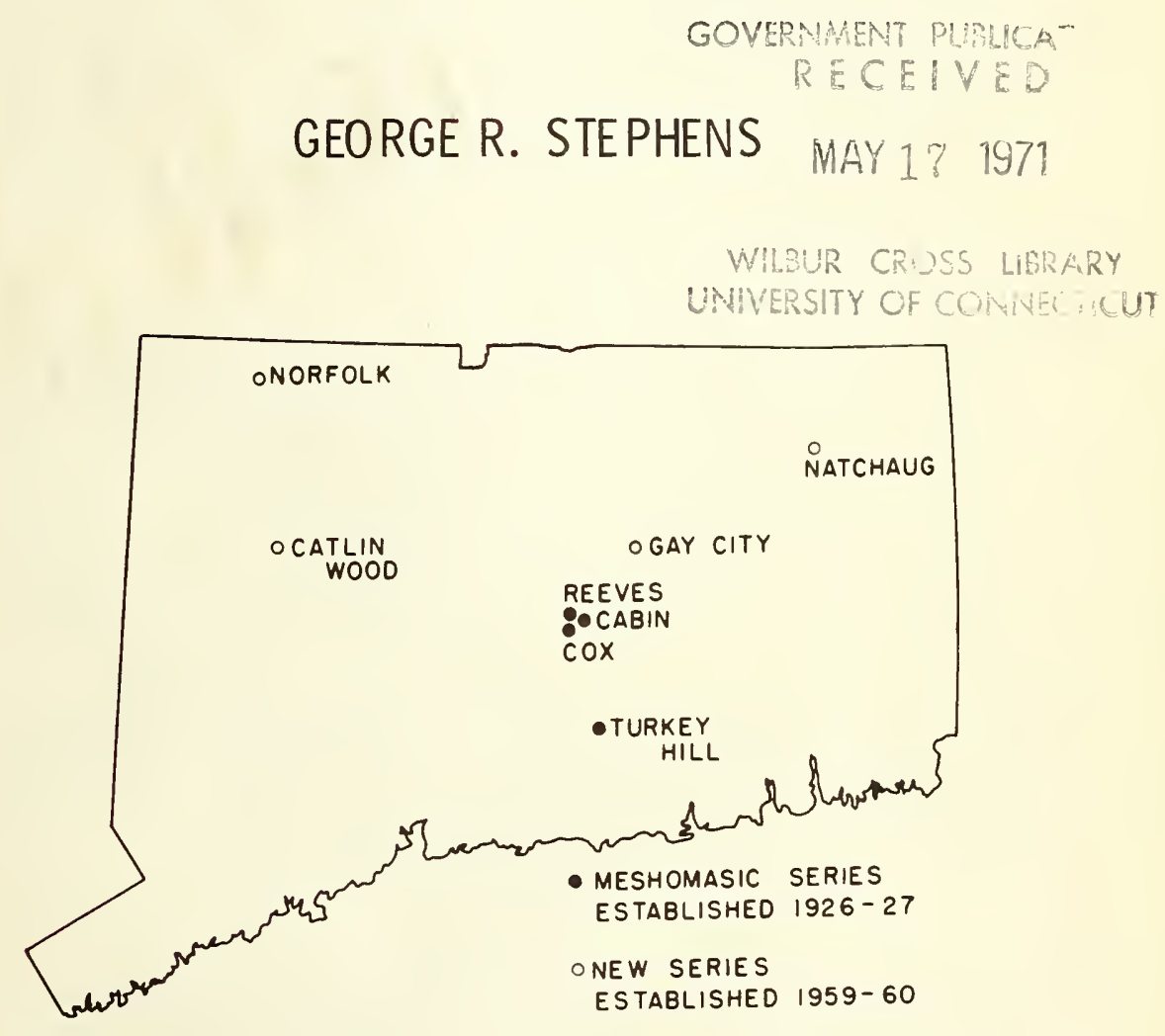

Location of the forest tracts sampled and reported herein.

BULLETIN OF THE CONNECTICUT AGRICULTURAL EXPERIMENT STATION, NEW HAVEN - No. 723, APRIL 197I 
Digitized by the Internet Archive in 2011 with funding from

LYRASIS members and Sloan Foundation 


\section{The Relation of Insect Defoliation \\ to Mortality in Connecticut Forests}

GEORGE R. STEPHENS

Recent severe defoliation of portions of Connecticut's hardwood forest by insects and the likelihood of continued defoliation in many areas has alarmed many citizens. They are apprehensive that massive or repeated defoliation will kill many trees. Clearly, sensible decisions on whether to control noxious defoliators require knowledge of the relation of defoliation to tree mortality. This report will describe mortality in defoliated forests in Connecticut, compare it to mortality in undisturbed forests, present observed differences in mortality among species groups and relate mortality in Connecticut forests to that in similar forests of other areas.

\section{The Forests}

The observations reported here were obtained by sampling eight forest tracts scattered across Connecticut (Cover). Four, called the Meshomasic series, are in the Meshomasic and Cockaponset State Forests of Middlesex County and have been described (Stephens and Waggoner 1970). The remainder, called the New series, are more widely scattered: Gay City State Park, on the border of Hartford and Tolland Counties; Natchaug State Forest in Windham County; Catlin Wood and Norfolk in Litchfield County. This New series has also been described (Stephens and Hill 1971).

The stands in the Meshomasic series are essentially evenaged, presently 70 to 85 years old. In the New series Gay City and Natchaug are also evenaged but younger than the Meshomasic tracts. Norfolk and Catlin Wood are older and unevenaged. Norfolk has two age groups; many of the larger trees are 80 to 90 years, and the younger group is about 60 years old. In Catlin Wood the oldest trees are approximately 185 years and trees of all ages are present.

All stems greater than 0.5 inch diameter breast high, d.b.h., (4. 5 feet above ground) were located, identified and described on nearly 12 acres of the Meshomasic series. Enumerations in 1927, 1937, 1957 and 1967 provided an accurate record of trees persisting, of ing rowth, i.e. stems newly appearing, and of mortality, i.e., individuals dying. In the New series similar enumerations were accomplished in 1959 and 1970 on nearly 2 acres. The total areas of the sample were only 12 and 2 acres, but the sample areas were in fact, transects 16.5 feet wide running uphill and down, representing a full range of Connecticut conditions. Estimates of defoliation were obtained from unpublished annual defoliation maps in the files of the State Entomologist, New Haven. These maps, prepared from a combination of ground and aerial reconnaisance, indicated major defoliators and described broad defoliation categories for the forest, but not individual species. 
The tracts varied in elevation, topography, soils and drainage, but for convenience have been subdivided into four sites based on soil drainage. The wettest (1) is called muck, a wet, swampy soil sometimes covered with standing water. The moist site (2) included the very poorly drained and poorly drained soils common along streams or in valley bottoms. Medium moist (3) included the somewhat poorly drained, the moderately well drained and well drained soils. This site (3) generally occurred in midslope and normally supported good tree growth. The dry site (4) included the somewhat excessively drained and the excessively drained soils. This site (4) occurred on the ridgetops and upper slopes that were only thinly mantled with soil.

Six of the tracts contained mostly deciduous hardwoods. The distribution of species varied with tract and site, but in all 30 major tree species and 13 minor species, mostly shrubs, were represented. Among major species oaks, maples and birches were most numerous, but only the older, unevenaged Catlin Wood and Norfolk contained appreciable conifers, mostly hemlock.

\section{The Problem}

Chronic defoliation persists in the forest at all times, and the list of defoliators is long. However, it is the massive defoliation brought about by sudden increases in insectpopulations thatis alarming. Particularly frightening are voracious onslaughts by hordes of lepidopterous larvae. Repeated depradations by the alien gypsy moth continue to alarm us. More recently, however, infestations of the native fall and spring cankerworms, the elm spanworm or snow white linden moth and others have been equally noticeable. From the standpoint of effect on trees, however, the essential elements are probably the time of defoliation and the amount of foliage removed; the identity of the defoliators that chew the leaves is secondary. Accordingly, in what follows defoliation, not defoliator, is emphasized.

\section{$\underline{\text { Normal Mortality }}$}

Mortality of trees in the forest is a continuous natural process. It results from competition among trees and shrubs for light, water, nutrients and growing space. Small endemic populations of insects and disease organisms exert a relentless pressure. Less frequent events such as ice, wind and lightning exact a small toll. The net result is a steady drain on the forest population, which is partially offset by ingrowth. 
For example, in a young, evenaged forest the population may be several thousand stems per acre. Losses over a decade are great and the mortality rate, expressed as the ratio of stems lost to population at the beginning of the loss period, is high. As the forest matures the losses decrease and the mortality rate may also decline. Finally in an old, unevenaged forest there is a slow turnover among stems: mortality is nearly balanced by ingrowth and the population remains nearly constant. This change in population and mortality can be seen in observations from the Meshomasic series during 1927-67 (Fig. 1).

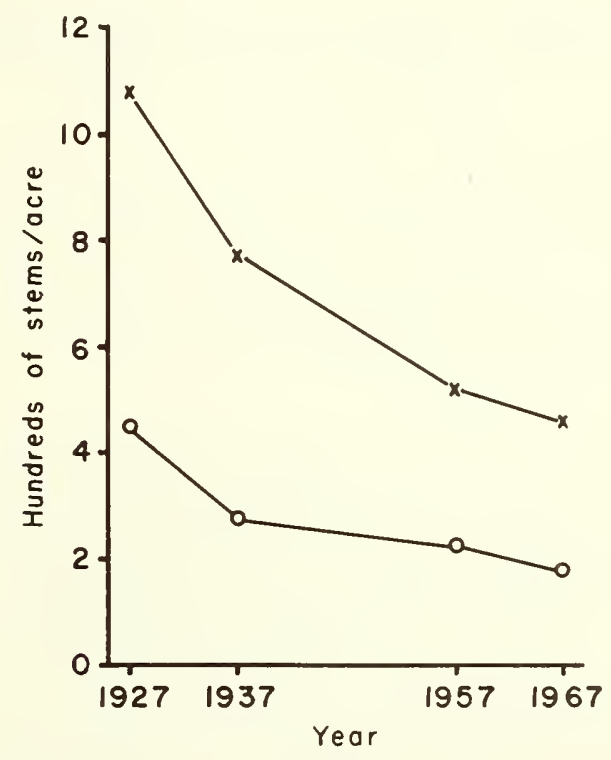

Figure 1. Population change in the Meshomasic series during 1927-67 for major species $(\mathrm{x})$ and minor species (o).

Mortality in undefoliated, undisturbed stands is described in Fig. 2. Both trees and shrubs died, but we shall consider only major tree species. The upper portion of Fig. 2 compares loss in major species during 1927-37 to the total population of trees and shrubs in 1927 in the Meshomasic series. During this decade defoliation was never severe enough to be mentioned by any observers. The numbers $1,2,3$ and 4 indicate the sites from wettest to driest, and the line is the trend or straight line that best fits the observations. As the population decreases, so does mortality. Note, however, that mortality in the wetter sites generally lies below the trend, whereas it is above on the drier sites. 


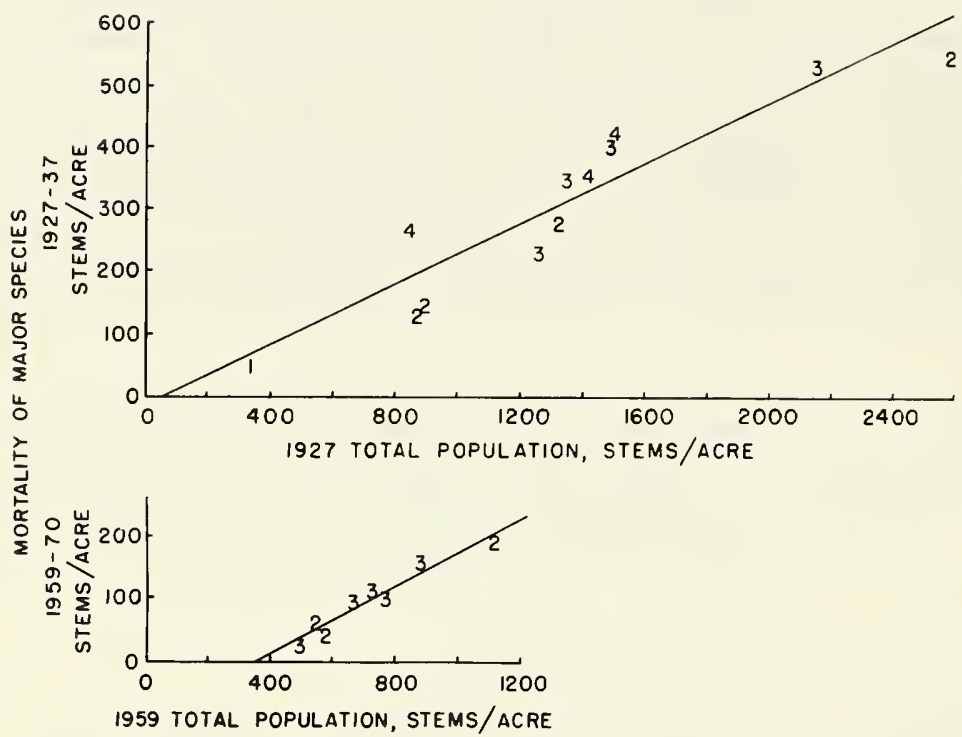

Figure 2. Periodic mortality of major species in tracts without major defoliation. The numbers are the sites: muck (1), moist (2), medium moist (3) and dry (4). The line is the straight line that best fits the observations. Upper. Meshomasic series, 1927-37. Lower. Natchaug, Norfolk and Catlin Wood of the New series, 1959-70.

The lower portion of Fig. 2 portrays mortality in three undefoliated, undisturbed tracts of the New series in a recent time, 195970. None of the sites were as wet nor dry as some in the Meshomasic series. Although in 1956, before the census of trees began, Catlin Wood had been more than half defoliated by gypsy moth, its mortality during 1959-70 did not differ from that of undefoliated Natchaug or Norfolk. This suggests that any effect of a prior defoliation on mortality is short-lived. The trend line fits the observations well and, despite differences in age, it is similar to that of the Meshomasic series in an earlier decade. Note, however, that for a given population, mortality in the New series during $1959-70$ was less than in the Meshomasic series during 1927-37. Thus even in different decades, mortality had a similar trend in undefoliated stands, increasing with population and with dryness of site.

Because percent mortality changed with population and site, it is meaningless to assign an average value to an entire forest. However, in the discussion of defoliation which follows we can compare the trend in undefoliated forests with mortality in defoliated ones. 


\section{Mortality in Defoliated Stands}

What effect does defoliation have on mortality in the forest? Surely much depends on the amount of foliage removed and the time of removal. Severe defoliation at any time deprives the tree of its ability to perform the basic assimilation process, photosynthesis. Defoliation early in the growing season is especially critical because new foliage does not immediately become functional and it is produced at the expense of stored reserves. Therefore, if severe defoliation necessitates production of a second set of leaves, reserves are still further depleted, leaf size and number and radial growth may be reduced (Duncan and Dodson 1950, Houston and Kuntz 1964, Nichols 1968) and the tree rendered susceptible to attack by other insects or diseases.

During 1957-67 all tracts in the Meshomasic series were defoliated. Cox, Cabin and Reeves were each defoliated three times. In 1961 a mixture of defoliators, cankerworms, gypsy moth and others, removed less than half the foliage; in 1962 they removed more than half the canopy. In 1963 a gypsy moth infestation defoliated Cox and Cabin less than half but portions of Reeves more than half. In 1964 gypsy moth defoliated Turkey Hill between 25 and 75 percent.

The upper portion of Fig. 3 indicates mortality during 1957-67 on the Meshomasic series. As before, numbers denote site. All uncircled numbers are from the once defoliated Turkey Hill. The three observations with great populations in 1957 are a portion of the tract burned in 1932 and allowed to recover. Since its composition is similar to the remainder of the tract, it is a younger stage. The circled observations are from the thrice-defoliated Cox, Cabin and Reeves tracts. The line is not the best fit to these observations; rather, it is the mortality trend observed in the undefoliated tracts of the New series during 1969-70 (Fig. 2, lower). Note that mortality on the once-defoliated Turkey Hill cannot be distinguished from mortality in undefoliated tracts of the New series. On the other hand, mortality in the thrice-defoliated tracts clearly lies above the line, especially in the drier sites.

The lower portion of Fig. 3 shows the mortality observed during 1959-70 at Gay City in the New series. In 1962 a mixture of defoliators removed less than half of the foliage on the dry ridgetop but more than half on the remainder of the tract. In 1967 the dry ridgetop was undefoliated, while the remainder was more than 75 percent defoliated by the oak leaf tier or other closely related insects. The uncircled 4 in Fig. 3 (lower) indicates mortality on the oncedefoliated dry site. The circled values represent the twice-defoliated moister sites. As before, the line in Fig. 3 (lower) represents mortality observed during 1959-70 in undefoliated Natchaug, Norfolk and Catlin Wood (Fig. 2, lower). Mortality on the once-defoliated 


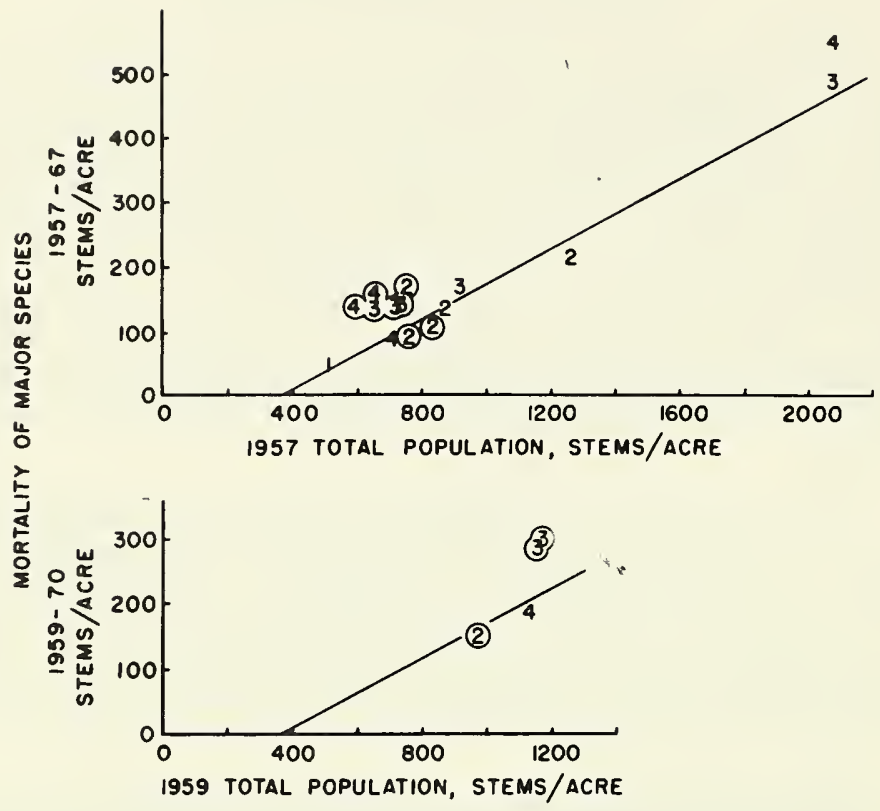

Figure 3. Periodic mortality of major species in tracts with major defoliation. The sites are as in Fig. 2. The line is the mortality trend observed during 1959- 70 in undefoliated tracts (Fig. 2 lower). Upper. Meshomasic series, 1957-67. Uncircled numbers are from Turkey Hill defoliated in 1964. Circled numbers are from Cox, Cabin and Reeves defoliated in 1961, 1962 and 1963. Lower. Gay City, 1959-70. Uncircled 4 is dry site defoliated in 1962. Circled numbers are the moister sites defoliated in 1962 and 1967.

dry site (4) and the twice-defoliated moist site (2) does not differ from that on the undefoliated tracts. On the medium moist sites (3), however, mortality is clearly greater.

These results correspond to a reconnaisance of mortality in western Connecticut (Stephens 1963). There little mortality occurred on dry ridgetops or moist valley bottoms during the first summer after severe defoliation by gypsy moth. Mortality was greatest on the midslope position where trees usually grow well. 
Thus, we see that a single defoliation within a decade did not increase mortality beyond that observed in undefoliated stands. Repeated defoliation, however, did increase mortality on medium moist sites and three consecutive defoliations increased mortality on dry sites also. After repeated defoliation mortality increased from a fourth to twice that observed in undefoliated stands. For example, in the Meshomasic stands with median population of about 700 stems per acre, expected mortality might be 100 stems per acre in a decade without serious defoliation; in a decade with three consecutive defoliations mortality ranged from no increase to about 150 stems per acre. Therefore, it seems unlikely that similar defoliation by itself will completely decimate the forest.

\section{$\underline{\text { Loss of Basal Area }}$}

We can evaluate mortality in another way. Numbers indicate only that trees died, but not whether they were large or small. On the other hand, basal area, the sum of the cross-sectional area determined from d.b.h. of all trees, can reveal something of the size of trees. For example, the basal area of 1000 trees each with 2 inch d.b.h. is only 22 square feet, but of 50 trees, each with 20 inch d.b.h., it is 109 square feet. Therefore, many small trees must die before loss of basal area equals that of a single large tree.

During 1927-37 loss of basal area by major species in the undefoliated, evenaged stands of the Meshomasic series was less on tracts whose basal area was less, and differences among sites were less apparent than for mortality of stems. In a more recent time, 1959-70, basal area loss in undefoliated Norfolk and Catlin Wood was nearly constant regardless of stand basal area. In these older stands with few stems and great basal area apparently only small trees died.

Losses of basal area in defoliated stands are revealed in Fig. 4. The upper portion shows basal area loss during 1957-67 in the Meshomasic series. The uncircled numbers are observations from oncedefoliated Turkey Hill; the circled, from thrice-defoliated Cox, Cabin and Reeves tracts. The line is the relation between basal area loss and existing basal area on all tracts of the Meshomasic series during 1927-37. During 1957-67 losses on the once-defoliated Turkey Hill generally equal or are less than the earlier trend. Observations from tracts with repeated defoliation generally lie above the trend.

The lower portion of Fig. 4 depicts basal area loss in Gay City during 1959-70. The trend line is the same as in the upper portion, and loss of basal area has the same pattern as stem mortality (Fig. 3, lower). The once-defoliated dry site and twice-defoliated moist site had less basal area loss than the twice-defoliated medium 


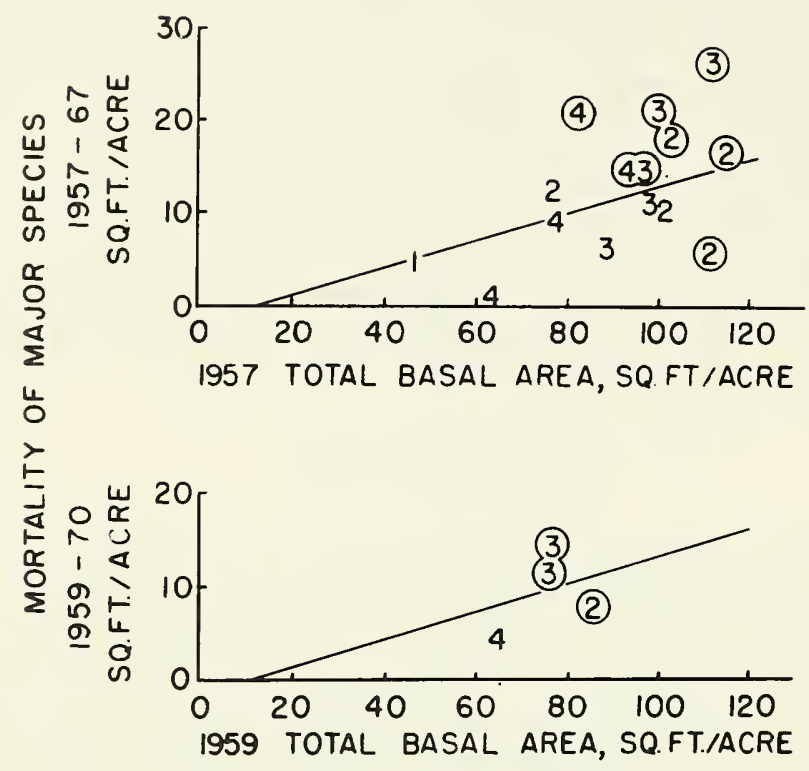

Figure 4. Periodic basal area loss of major species in tracts with major defoliation. The sites are as in Fig 2. The line is the trend of basal area loss observed during 1927-37 in the Meshomasic tracts. Upper. Meshomasic series 1957-67. Uncircled numbers are from Turkey Hill defoliated in 1964. Circled numbers are from Cox, Cabin and Reeves defoliated in 1961, 1962 and 1963. Lower. Gay City, 1959-70. Uncircled 4 is the dry site defoliated in 1962. Circled numbers are the moister sites defoliated in 1962 and 1967.

moist sites. However, if we compare numbers of stems lost (Fig. 3) with basal area lost (Fig. 4), we conclude that the many trees that died at Gay City during 1959-70 must have been small whereas the fewer trees dying during 1957-67 on Cox, Cabin and Reeves must have included larger stems.

\section{Losses among Canopy Trees}

How great is the toll among the larger trees whose crowns comprise the main canopy of the forest? During a decade without serious defoliation, 1927-37, mortality of stems in the canopy of the Meshomasic tracts was less where the number of stems participating in the canopy was less and the relation was similar to that in Fig.2, 
upper. On the other hand, loss of basal area was nearly constant regardless of the total basal area of trees in the canopy. During a later decade with defoliation, 1957-67, losses on once-defoliated Turkey Hill were similar to the earlier period, but on Cox, Cabin and Reeves, defoliated three times, losses were greater both in number of stems and basal area. Although a single average loss cannot be assigned, loss of trees in undefoliated canopies was generally 10 percent or less in a decade and basal area loss ranged from 1 to 17 percent. After three consecutive defoliations loss of stems in the canopy ranged from 8 to 26 percent and basal area losses were 4 to 23 percent. Generally, losses were higher on the medium moist and dry sites than on the moist.

Thus we conclude that a single defoliation has little effect on trees in the canopy, but repeated defoliation increases losses, particularly on the drier sites.

\section{Differences Among Species Groups}

The results presented so far were average mortality of all major tree species present. Do all species or groups respond alike or do some die more readily after defoliation? Table 1 contains the summary of average mortality of maples, oaks and all major species on undefoliated sites and for those with one, two or three defoliations in a decade. The maples were red and sugar maple and the oaks included red, black, scarlet, white and chestnut oak. All of these were in the Meshomasic series and all but chestnut oak were in the New series.

Oaks generally had greater mortality of stems than maples and this was verified in three of four observations of defoliation (Table 1). For example, on Turkey Hill during a decade without major defoliation, 1927-37, mortality of maple was less and oak greater than the stand average (Table 1, A). During a later decade with a single major defoliation, 1957-67, the proportion of maple or of all trees dying remained unchanged, but mortality of oaks increased (Table 1, A). During an early decade without major defoliation on Cox, Cabin and Reeves tracts mortality of oaks was only slightly higher than maple and both were near the stand average (Table 1, B). We do note that mortality here was generally greater than at Turkey Hill. The cause is not readily apparent, although Turkey Hill was less heavily populated than the other tracts during 1927-37 (Stephens and Waggoner 1970). However, during 1957-67 with three consecutive defoliations, mortality of maple and of the stand decreased to nearly the same level as on Turkey Hill, but mortality of oaks increased greatly (Table 1,B). Thus mortality of maple remained low and less than half that of oak, despite one or three defoliations. 
Losses among trees in undefoliated canopies were similar. During 1927-37 loss of oaks in the canopy of Turkey Hill averaged 18 percent while on Cox, Cabin and Reeves 17 percent died. At the same time no canopy maples died at Turkey Hill and only one percent were lost on the remainder of the Meshomasic tracts. During 1957-67 loss of canopy oaks at once-defoliated Turkey Hill decreased to 10 percent whereas it increased to 25 percent on the remaining Meshomasic tracts. On the other hand, loss of maples scarcely changed. Further, loss of canopy oaks after repeated defoliation was not as great as loss of understory oaks. Nevertheless, it is clear that repeated defoliation can increase loss of large oaks, but it has little effect on maples.

Basal area loss on all tracts of the Meshomasic series was similar during 1927-37 when defoliation was negligible, but marked differences occurred during 1957-67 (Table 1, A and B). Loss of oak basal area in once-defoliated Turkey Hill was slight, but it increased greatly on Cox, Cabin and Reeves tracts, which were defoliated in three successive years. Therefore, we see that small oaks died at Turkey Hill whereas larger ones succumbed after repeated defoliation of the other tracts.

In the New series mortality of maple and oak stems during 1957-70 on Natchaug, Norfolk and Catlin Wood, which received no major defoliation (Table 1, C), differed little from Turkey Hill defoliated once during 1957-67 (Table 1,A). On the more moist sites of Gay City, defoliated twice during 1959-70, few maples but many oaks died (Table 1, D). The increase in average mortality of all major species reflects both the abundance in 1959 and great loss of oak during 1959-70. The sole exception to greater mortality of oak than maple occurred on the once-defoliated dry site of Gay City (Table 1, E). Mortality of oak was unusually low even compared to undefoliated tracts, but the reason is not apparent.

On the twice-defoliated sites of Gay City nearly three-fourths of the oak stems died but only slightly more than a third of oak basal area was lost (Table 1, D). We conclude that mostly small oaks died here.

Although not shown in Table 1, black and yellow birches responded similarly to maple on most sites and tracts. Thus, oaks appear generally less able to survive defoliation than maples or birches.

Even among oaks mortality differed. During 1957-67, despite defoliation, relatively few red oaks died in the Meshomasic series whereas many white and chestnut oaks succumbed. Loss of black and scarlet oak was intermediate (Stephens and Waggoner 1970). In the New series mortality of white oak was greater than that of red during 1959-70; black oak was intermediate (Stephens and Hill 1971). 
Table 1. Periodic mortality (percent of total)

\begin{tabular}{|c|c|c|c|c|c|c|}
\hline \multirow{2}{*}{\multicolumn{2}{|c|}{ Meshomasic serie }} & \multicolumn{2}{|c|}{ Undefoliated } & \multicolumn{3}{|c|}{ Defoliated } \\
\hline & & \multirow{2}{*}{\multicolumn{2}{|c|}{$\frac{1927-37}{\text { Mortality }}$}} & \multicolumn{3}{|c|}{ 1957-67 } \\
\hline \multirow{2}{*}{\multicolumn{2}{|c|}{ Species Group }} & & & \multirow{2}{*}{$\begin{array}{l}\text { Number of } \\
\text { Defoliations }\end{array}$} & \multicolumn{2}{|c|}{ Mortality } \\
\hline & & Stems & Basal Area & & $\underline{\text { Stems }}$ & Basal Area \\
\hline \multirow[t]{3}{*}{ A. } & Maple & 16 & 9 & 1 & 15 & 9 \\
\hline & Oak & 33 & 9 & & 41 & 6 \\
\hline & All major & 26 & 12 & & 27 & 12 \\
\hline \multirow[t]{3}{*}{ B. } & Maple & 31 & 13 & 3 & 19 & 10 \\
\hline & Oak & 35 & 9 & & 48 & 27 \\
\hline & All major & 34 & 13 & & 28 & 16 \\
\hline
\end{tabular}

New series

C. Maple

Oak

All major

D. Maple

Oak

All major

E. Maple

Oak

All major
$1959-70$

$15 \quad 1$

$38 \quad 10$

17

6

2 $1959-70$ 
One possible reason for the lesser mortality of maples and birches compared to oaks is the difference in degree of defoliation. Defoliation estimates were for the stand as a whole and not for individual species. Oak is a preferred host for most of the defoliators mentioned. The observations include no known severe defoliation by elm spanworm. This insect preferentially attacks red maple and yellow birch common to the moister sites. Plumb and Friend (1939) reported severe defoliation of these species by elm spanworm in Connecticut in 1938. They further commented that during an earlier outbreak in Massachusetts red maple suffered nearly complete defoliation and yellow birch, 60 to 65 percent. Complete stripping for two or three seasons resulted in the death of practically all of the red maple.

None of the defoliated stands contained many conifers. Therefore, for effect of defoliation on conifers we must rely on the observations of House (Turner 1963). During five years after a single defoliation by gypsy moth, which removed 90 percent or more of their foliage, two-thirds of hemlock and a fifth of white pine died. Hemlock mortality was greater for trees in the canopy whereas mostly overtopped white pine died. Four-fifths of hemlock mortality occurred the first year after defoliation; two-thirds of white pine mortality occurred in two years, with about 40 percent in the second year. No hemlock and only one percent of white pine died within five years after being less than 90 percent defoliated.

We learn two things: defoliation, especially repeated defoliation, increased mortality of oak but affected maple little; and, even in undefoliated stands, loss of oak stems was proportionally greater than loss of maple or of all major species. This decline of oak in Connecticut's forest has been occurring since at least 1927 (Stephens and Waggoner 1970) and perhaps represents a gradual change in forest composition now that the forest has been spared repeated burning and clearcutting.

Unfortunately, the observation periods were 10 or 11 years. Only slight increases in the mortality for the entire decade accompanied repeated defoliation during the decade. However, much of the defoliation occurred during the middle of the observation period and the record does not indicate whether defoliation was followed immediately by great mortality. If this were the case, the thinning effect of high mortality in a single year would likely reduce mortality in subsequent years. The net result might be only a slight increase in mortality for the period, an observation already made. However, it is also clear that even repeated defoliation has not more than doubled expected losses during a decade in our forests. 


\section{Mortality in Other Areas}

How does mortality in Connecticut's forests compare to other areas? Baker (1941) reported mortality following gypsy moth defoliation in eastern New England. During the decade, 1912-21, about 30 percent of favored food species and 13 percent of unfavored species died after one or more defoliations. Thrifty trees seldom died after a single complete defoliation. Once defoliation of individual trees exceeded 20 percent, average mortality quickly rose to about 10 percent in the year after defoliation. At the same time, however, mortality of undefoliated trees was more than four percent, higher than that observed in Connecticut (Fig. 2). Attack by the two-lined chestnut borer and shoestring fungus (Armillaria mellea (Vahl.) Quil.) was often associated with mortality of defoliated trees.

Turner (1963) summarized the observations of Tierney during 1934-47 in the Connecticut River Valley of Massachusetts. Defoliation by gypsy moth occurred from one to eight times in 13 years on 34 areas comprising 2641 acres. In 1947 two-thirds of the area showed an estimated 10 to 50 percent mortality, and one-third, 40 to 75 percent. On areas defoliated only once, mortality ranged from 10 to 40 percent, and in some portions, to 75 percent. Similar mortality was observed on repeatedly defoliated areas and, frequently, mortality of oak was great.

Nichols (1968) reported mortality of oaks in Pennsylvania during 1953-66. Twenty defoliators were active, but the oak leaf tier was considered most important. Generally, two consecutive defoliations exceeding 60 percent were required to kill, and in about one-fourth of the cases, three consecutive defoliations were necessary. Nearly all dead or dying trees were infested with the two-lined chestnut borer. High mortality, 10 percent annually, persisted for only one year after defoliation. Moderate mortality, five percent annually, persisted an average of three years. More recently Nichols (1970) reported that an infestation of the oak leaf roller had badly defoliated oak stands in northern Pennsylvania. Resulting mortality was typically 30 to 50 percent, but reached 80 to 90 percent in some locations. Most trees required two consecutive defoliations before death, and defoliation in three consecutive years was usually fatal. Again, attack by the twolined chestnut borer killed trees weakened by defoliation.

Similar trends in mortality following defoliation occur in forests like those in Connecticut. However, some losses reported appear much greater than those recorded in Connecticut. It is interesting to recall the opinion of House (1952) and others that mortality after defoliation by gypsy moth was less in Connecticut and Rhode Island because "... a degree of resistance exists which even in years of heavy buildup causes mortality losses to be considerably under the average for other areas of New England." The observations reported in this bulletin tend to substantiate House's statement. 


\section{Conclusion}

What conclusions may we draw from the observations? Unfortunately, the picture is not entirely clear because we cannot say what the outcome will be immediately after a single severe defoliation or after several successive defoliations. Over the longer term, say a decade, it appears that a single defoliation will not increase mortality. Repeated defoliation, however, will increase mortality and cause some large trees to die, but over a decade the increase in mortality is not more than a doubling. Oaks die more readily than maples or birches, and among the oaks, white and chestnut oak succumb more rapidly than red oak. Mortality after defoliation in Connecticut forests has not always been as great as that reported elsewhere. Therefore, if we can rely on past observations, then large-scale destruction of our forests by defoliation seems unlikely.

\section{Acknowledgments}

The author thanks H. A. McKusick, State Forester, and D. M. Smith of the Yale School of Forestry for reading the manuscript critically. 


\section{$\underline{\text { Literature Cited }}$}

Baker, W.L., 1941. Effect of gypsy moth defoliation on certain forest trees. J. For. 39:1017-1022

Duncan, D.P. and P.C. Hodson, 1958. Influence of the forest tent caterpillar upon the aspen forests of Minnesota. For. Sci. 4:71-93

House, W.P., 1952. Appraisal of damage by the gypsy moth in New England 1933-52. U.S.D.A., Agr. Res. Admin., Bur. Ent. Plant Quarantine, Gypsy Moth Control Proj. 22p. (mimeo).

Houston, D.R. and J.E. Kuntz, 1964. Pathogens associated with maple blight. p. 59-79. In Studies of maple blight. Univ . Wisconsin, Madison. Res. Bull. 250.

Nichols, J.O., 1968. Oak mortality in Pennsylvania - a ten year study. J. For. 66:681-694.

Nichols, J.O., 1970. Oak mortality. Penn. Dept. Forests and Waters, Harrisburg. Forest Pest Rep. No. 43. 2 p.

Plumb, G.H. and R.B. Friend. 1939. An outbreak of the elm spanworm in Connecticut, 1938. p. 98-102. In Britton, W.E., Connecticut State Entomologist Thirty-eighth report. The Conn. Agr. Expt. Sta., New Haven. Bull No. 428.

Stephens, G.R., 1963. Tree mortality resulting from defoliation in 1962. The Conn. Agr. Expt. Sta., New Haven. Dep. Entomol. Rep. of Progress No. 15. 2 p.

Stephens, G.R. and D.E. Hill, 1971. Drainage, drought, defoliation and death in unmanaged woodlands of Connecticut. The Conn. Agr. Expt. Sta., New Haven. Bull. No. 718 (In preparation).

Stephens, G.R. and P.E. Waggoner, 1970. The forests anticipated from 40 years of natural transitions in mixed hardwoods. The Conn. Agr. Expt. Sta., New Haven. Bull. No. 707. 58 p.

Turner, N. (ed.), 1963. Effect of defoliation by the gypsy moth. The Conn. Agr. Expt. Sta., New Haven. Bull. No. 658. 30 p. 
Common and scientific names of trees and insects mentioned in this report.

\section{TREES}

\begin{tabular}{|c|c|}
\hline Birch, black & Betula lenta $\mathrm{L}$. \\
\hline Birch, yellow & Betula alleghaniensis Britton \\
\hline Hemlock & Tsuga canadensis (L.) Carr. \\
\hline Maple, red & Acer rubrum $\mathbf{L}$. \\
\hline Maple, sugar & Acer saccharum Marsh. \\
\hline Oak, black & Quercus velutina Lam. \\
\hline Oak, chestnut & Quercus prinus $\mathrm{L}$. \\
\hline Oak, red & Quercus rubra $\mathrm{L}$. \\
\hline Oak, scarlet & Quercus coccinea Muenchh. \\
\hline Oak, white & Quercus alba $\mathrm{L}$. \\
\hline Pine, white & 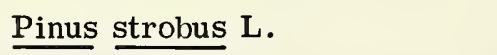 \\
\hline \multicolumn{2}{|c|}{ INSECTS } \\
\hline Elm spanworm & Ennomos subsignarius Hbn. \\
\hline Fall cankerworm & Alsophila pometaria Harris \\
\hline Gypsy moth & 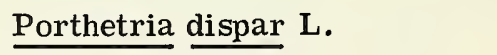 \\
\hline Oak leaf roller & Archips semiferanus \\
\hline Oak leaf tier & Croesia semipurpurana Kearf. \\
\hline Spring cankerworm & Paleacrita vernata Peck. \\
\hline
\end{tabular}



THE CONNECTICUT AGRICULTURAL EXPERIMENT STATION NEW HAVEN, CONNECTICUT 06504

fans \& torsfeels

PUBLICATION

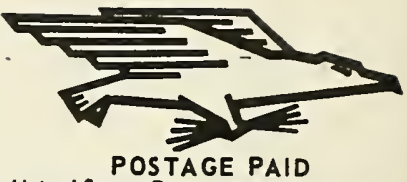

Unired Stotes Department of Agriculture 
University of
Libraries 


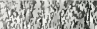

